\title{
The job satisfaction gender gap among young recent university graduates: Evidence from Catalonia
}

\author{
Toni Mora* \\ School of Economics and Social Sciences, Universitat Internacional de Catalunya \\ and \\ Ada Ferrer-i-Carbonell \\ Faculty of Economics and Business (SCHOLAR), AIAS, \& Tinbergen Institute, University of \\ Amsterdam
}

*Full address for correspondence: Toni Mora, School of Economics and Social Sciences, Universitat Internacional de Catalunya, Immaculada, 22, 08017, Barcelona (Spain) Phone 0034 932541800 (4511) Fax 0034932541850. Email: amora@cir.uic.es

Acknowledgements: The Quality Assurance Agency for the University System in Catalonia, and especially Anna Prades, for supplying the data. Toni Mora gratefully acknowledges the financial support of the Spanish Ministry of Science and Technology given under grant SEJ2006-01161/ECON.

Word count: 6,511

Date: 29-11-2006 


\title{
The job satisfaction gender gap among young recent university graduates: \\ Evidence from Catalonia
}

\begin{abstract}
The present paper focuses on the gender differences in job satisfaction reported by recent university graduates in Catalonia (Spain). The data allows to distinguish five areas of job satisfaction: work content, promotion possibilities, earnings, applicability of acquired knowledge, and job security. The empirical analysis shows that there is a gender gap in job satisfaction and that this can be (largely) attributed to the worse employment conditions women face. This is surprising given the nature of the sample, i.e. very young and highly educated. The paper concludes that while young women's expectations have risen, their labor market achievements have not improved at the same pace. The data set consists of more than 3,000 individuals who graduated in 1997-1998 and were interviewed in 2000.
\end{abstract}

Key words: Gender gap; job satisfaction; employment conditions.

JEL codes: I20; J28; J31. 


\section{Introduction}

This paper analyses the gender gap in the labor market. While most research has focused on the gender earnings gap and on other objectively defined job characteristics, few researchers have looked at the gender differences on perceived job quality. This is a relevant question to the extent that many western countries have as an important point in their policy agenda the increase of female participation in the labor market. Understanding female job satisfaction is therefore an important ingredient to policymaking to the extent that individual's participation in the labor market depends on the satisfaction they derive from it. In the 2002 Employment in Europe Report ${ }^{1}$ by the European Commission (p.98), it is clearly recognized that job satisfaction positively correlates with labor market participation, especially of women. Knowing whether women are or are not less satisfied with their job is however not enough information if we aim at increasing women's job satisfaction. Instead, we need to better understand and disentangle the reasons behind reported job satisfaction. This paper does that by looking not only at reported job satisfaction, but also examining gender differences in employment conditions, educational choices and attainments, and at the combination of both while controlling for personality traits. Because of the systematic analysis, we can be fairly certain that we are able to isolate the reason for the gender differences in job satisfaction.

Past research on the gender differences in job satisfaction (Clark, 1997; Kaiser, 2005; Sousa-Poza and Sousa-Poza, 2003) has concluded that given everything else, women are in most countries more satisfied with their job than men. This gender gap in favor of women has been attributed to the lower job expectations that women have as compared

\footnotetext{
${ }^{1}$ http://ec.europa.eu/employment_social/news/2002/sep/employment_in_europe2002.pdf
} 
to men. This conclusion relies on the following findings: very young and highly educated women in Clark’s (1997) British sample report the same overall job satisfaction and a lower satisfaction with pay than men in these same categories; in EU countries in which women working conditions are better (Denmark, Finland, and The Netherlands) there is no gender gap in job satisfaction (Kaiser, 2005); and the job satisfaction gender gap favorable for women has been reduced by halve from 1991 to 2000 in the UK (Sousa-Poza and Sousa-Poza, 2003).

This paper contributes to the literature not only by disentangling the reasons for the gender gap in job satisfaction but also by looking at a very young cohort of highly educated (tertiary education) individuals in Catalonia (a region situated in the north-east of Spain). Not only have young and highly educated women probably different expectations than their mothers did, but moreover child bearing and caring has mostly not yet interrupted their careers. Until now researchers have argued that women expectations may change as their employment conditions improve. This change, they argue, will reduce the gender gap in job satisfaction found in the literature. Therefore, the use of the present sample will be useful to test whether women expectations have changed. The region of study is also interesting on that its labor market characteristics have many features in common with the countries of South Europe, where women face worse employment conditions than in other northern EU countries. For example, SousaPoza and Sousa-Poza (2000, p.141) write, “one result that does catch our attention is that women in Spain have a much lower satisfaction-level than men...”.

The data comes from a sample of individuals who graduated in 1997-1998 from any of the seven public Catalan universities. Catalonia (Spain) has a female activity rate that, 
although higher than the average in Spain, is lower than the Northern EU countries. In 2005, the women (16-64) participation rate in Catalonia was 65.2 percent, while in the total of Spain it was 59.1 percent $^{2}$. These numbers contrast with countries like Sweden and Denmark were female activity rates are over 70 percent $^{3}$ and with the Lisboan target of 70 percent by $2010^{4}$. If we want to meet such targets, women incentives to enter the labor market should improve. Nevertheless, the gender gap in the labor market is still a fact in Catalonia in particular and in Spain in general. For example, the gender pay gap in unadjusted form as reported by Eurostat ${ }^{5}$ in 2004 for Spain was 15 percent, which equals the average of the EU25 and EU15. The existence of a gender pay gap indicates that women have access to other type of jobs than men. For example, statistics show that women participation in managerial occupations is much lower than for men and that there is a clear gender sectorial segregation. Despite this, Spain and Catalonia have a large proportion of women that attain higher education. For example, for the whole Spain, 59.9 percent of the individuals who graduated in the academic year 1997-1998 were women. For Catalonia this number equals 58.59 percent. Since for highly educated individuals the activity rate between men and women is very similar ${ }^{6}$, it is to be expected that women will slowly increase and improve their participation in the labor market. Using our data set, we will examine the gender differences on job satisfaction of individuals with tertiary education.

\footnotetext{
${ }^{2}$ Source: Idescat; http://www.idescat.net/economia/inec?tc=3\&id=5701\&lang=en

${ }^{3}$ Source: European Employment conditions Observatory; Annual review of employment conditions in the EU: 2004-2005.

${ }^{4}$ Source: Report on equality between women and men, 2006. European Commission.

5 http://europa.eu.int/estatref/info/sdds/en/earn/earn_gr_gpg_base.htm. See also Report on equality between women and men, 2006. European Commission.

${ }^{6}$ In Catalonia, the activity rate in 2001 of the least educated was 35.82 percent for men and 14.53 percent for women. For individuals with tertiary education (our sample), these percentages were 83.83 percent and 81.84 percent, respectively.
} 


\section{Testing strategy}

\subsection{Empirical approach}

The first question we like to address is whether there are gender differences in the five reported job satisfactions, i.e. satisfaction with work content, promotion possibilities, earnings, applicability of acquired knowledge, and job security. In this way, we can identify whether women are more or less satisfied with their job than men. As discussed in the introduction, it is important not only to look at gender differences in job satisfaction but also to try to understand why these differences arise. Only then, can one aspire to make sensible policy recommendations to increase women job satisfaction and thus participation in the labor market.

Job satisfaction is a subjective feeling that, although partly determined by an individual working situation, it also depends on an individual's perception of own job (how the job compares with his or her expectations) as well as on his or her personality (e.g. neuroticism and extraversion). Therefore, any gender differences in reported job satisfaction can be due to several factors, namely different employment conditions between men and women, persistent gender differences in expectations, and in personality traits. In order to understand and disentangle any gender differences in job satisfaction, we thus need to deepen into the empirical analysis.

First, we will look into the gender differences on the employment conditions, for example, wages, type of contract, number of worked hours, and occupation to see whether women achievements in the labor market are comparable to those of men. Since educational choices and attainments (e.g. degree obtained and field of study) 
partly determine the opportunities that individuals have in the labor market, the paper will also examine the gender differences in education.

In a final step, the paper will present an econometric analysis of job satisfaction in which we will control individual characteristics (e.g. age), employment conditions (e.g., wages, type of contract, and type of occupation), education attainments and choices (e.g. grades and field of study), and a variable capturing individual's personality traits. This analysis will indicate whether given everything else (i.e. an exact individual with the same job), gender differences prevail. If this is the case, there are two main candidates for these differences, i.e. systematic gender differences in expectations, or omission of relevant variables. This last explanation has been frequently (if not always) ignored by the literature. Nevertheless, it seems a rather obvious candidate for the gender job satisfaction gaps found in the literature since obtaining full information on an individual's employment conditions is a rather complicated enterprise. For example, researchers can be certain to have omitted job characteristics, such as the differential treatment that some workers receive or the capacity to negotiate salary. Thus, we can not exclude that relevant variables have been omitted in the analysis despite we can control for an unusual large number of job and educational characteristics due to the particularly rich data set at hand. Therefore, it is difficult to disentangle whether any gender differences are due to omitted variables or to different expectations between men and women. Nevertheless, the analysis in Section 3.3 provides a step forward on solving this puzzle.

\subsection{The job satisfaction question}


The empirical analysis is largely based on the individual's answer to a subjective job satisfaction question. This question contains information on the subjective evaluation that each individual does of his or her own work ${ }^{7}$. In the present data set, individuals are asked to report their satisfaction with five areas of their job, namely satisfaction with work content, promotion possibilities, earnings, applicability of acquired knowledge, and job security. This provides more information than when asking only about satisfaction with job in general. Individuals are asked to report the five partial job satisfactions on a discrete scale from 1 to 7 , where 1 stands for "completely unsatisfied" and 7 for “completely satisfied”.

For job satisfaction (or any measure of self-reported satisfaction) to be meaningful it has to correlate with the true theoretical concept we are interested in, i.e. reported job satisfaction has to have some connection with the economic concept of job utility. It is obviously difficult to probe such a preposition. Nevertheless, many empirical evidence points into this direction by showing a link between reported job satisfaction and individual's behavior. For example, job satisfaction is a good indicator of labor market mobility (Freeman, 1978), it can predict quits (Clark and Georgellis, 2004), and correlates with (women) participation in the labor market (European Commission, 2002). In addition, one needs to assume interpersonal comparability. At the ordinal level, this implies that individuals reporting a 6 are assumed to be more satisfied with their work than those reporting a 3. At the cardinal level, the distances between the answers provide information, i.e. someone reporting a 6 is twice as satisfied as someone reporting a 3. In this paper we will assume cardinality when necessary (comparing

\footnotetext{
${ }^{7}$ Other papers that use such job satisfaction are, for example, Clark, 1997, 1999, 2001; Clark and Oswald, 1996; Clark et al., 1996; Drakopoulos and Theodossiou, 1997; Groot and Maassen van den Brink, 1999; Sousa-Poza and Sousa-Poza, 2000; Van Praag and Ferrer-i-Carbonell, 2004; and Wottiez and Theeuwes, 1998
} 
average reported satisfaction between genders) and ordinality when possible. Ferrer-iCarbonell and Frijters (2004) have shown that imposing cardinality or ordinality does not change the nature of the results.

\subsection{The econometric technique}

In the empirical analysis, we estimate Job Satisfaction $\left(J S_{i}\right)$ of individual $i$ as a function of his or her individual characteristics, employment conditions and education choices and attainments $\left(Z_{i}\right)$. Next to the observable objectively measurable individual, job and education characteristics, job satisfaction is determined by individuals’ personality traits. Psychologists have long claimed that individual personality characteristics explain up to 80 percent of an individual self-reported satisfaction (Lykken and Tellegen, 1996). If the data is a panel, one can control for these by including individual effects. Since the present sample is cross-section, we need to find a more creative way to control for those psychological traits. The data set contains a set of questions indicating individual's perception of why they were selected for their present job. Here we use the answer to these questions, known as self-efficacy evaluation, to create a measure of individual personality $\left(P_{i}\right)$ by using factor analysis ${ }^{8}$, as usual in the selfevaluation literature (see Bono and Judge, 2003). This measure is highly correlated with self-esteem (Bono and Judge, 2003).

In order to accommodate for ordinality in the econometric analysis, the five job satisfactions are regressed with an Ordered Probit. This means that it is not possible to

\footnotetext{
${ }^{8}$ The Kaiser-Meyer-Olkin measure of sampling adequacy indicated that multivariate analysis obtains excellent results (the factor accounted for $95 \%$ of the overall variability). Subsequently, we re-scaled the factor predictions to [0-1], since the individual opinions on the determinants of being contracted should not have a negative value, whilst 1 should represent being fully confident in themselves.
} 
observe the exact level of job satisfaction (JS*), but only the range in which it lies (JS).

The job satisfaction model to be estimated is

$$
\begin{aligned}
& J S_{i}^{*}=\alpha+Z_{i} \beta_{1}+P_{i} \beta_{2}+\varepsilon_{i} \\
& J S=\mathrm{k} \Leftrightarrow \mu_{\mathrm{k}} \leq J S^{*}<\mu_{\mathrm{k}+1}
\end{aligned}
$$

where the usual error term $\left(\varepsilon_{i}\right)$ and a constant $(\alpha)$ are added. Following the usual ordinal probit notation, $J S^{*}$ describes the underlying non-observed variable, $J S$ is the observed variable, $k$ is one of the 7 categories ( 1 to 7 ), and $\mu$ are the estimated intercept terms. The results presented in the paper are obtained considering bootstrapping (500 replications) and robust standard errors.

\subsection{The data}

The empirical analysis is based on a data set provided by The Quality Assurance Agency for the University System in Catalonia (AQU). The survey was conducted in 2000 and covered all the individuals who graduated in the 1997-1998 academic year from one of the seven public Catalan universities. The main aim of this survey was to study the position of the university graduates in the labor market. In Catalonia there are twelve recognized universities, seven are public, four are private, and one is virtual. Of the total number of university students, the vast majority (nearly 80 percent) graduates from one of the seven public universities. Catalonia is one of the richest regions in Spain and has a total population of almost 7 million people. The capital of Catalonia is Barcelona, around where four out of the seven universities are located. 
The response rate was 48 percent. For this study, we eliminate all individuals younger than 34 (about 7 percent), i.e. we exclude those students who graduated at an older age and may have already much working experience. In doing so, we obtain a fairly homogenous sample of young highly educated individuals. After cleaning for age and for missing observations, we obtain a final sample of more than 3,000 individuals. The final sample consists of 61.94 percent of women. This amount is slightly larger than the percentage of female graduates in that same year in Catalonia (58.59 percent). The differences are however very small. Moreover the two numbers cannot be exactly compared, as the first one includes only the 7 public universities while the second one includes all the universities in Catalonia.

Next to including the above mentioned five partial job satisfactions (section 2.2), the data set contains information on the graduates' current and past job characteristics, such as, work experience, type of contract, access to training, type of occupation, region where the respondent works, and wages. In addition, there is information on individual characteristics, such as gender and age, and educational attainments and choices (e.g. final grades and field of study.

\section{The job satisfaction gender gap: empirical results}

\subsection{Job satisfaction}

As described in Section 2.2, the data set contains information on five partial job satisfactions, i.e. the self-reported individual subjective appreciation of their own job with respect to five areas. ${ }^{9}$ Table 1 shows the means of these satisfactions for the whole

\footnotetext{
${ }^{9}$ Principal components analysis evidences that one single partial job satisfaction can only explain a maximum of $46.27 \%$ of the overall variability. Hence, analysing each partial job satisfaction provides a better understanding of an individual job satisfaction than looking only at overall job satisfaction.
} 
sample and for men and women separately. It is important to remember that the answers are reported from 1 to 7, where 1 stands for “completely unsatisfied” and 7 for “completely satisfied”.

\section{[Insert Table 1 here]}

This table shows that women are less satisfied than men for three out of the five partial job satisfactions. These are: satisfaction with promotion possibilities, earnings, and job security. The other two satisfactions (satisfaction with the applicability of acquired knowledge and with work content) do not show statistically differences between genders.

The main aim of this paper is to understand why young highly educated women are less satisfied with many aspects of their job than their men companions. There are two main reasons one can think of: (1) men on women have different personality traits, experiences, and expectations; or (2) women have worse employment conditions than men. The first explanation implies that the way in which individuals translate their objective situation (the job they have) into a subjective evaluation (job satisfaction) systematically differs between genders. The second means that women and men do not have access to the same type of jobs and that, on average, women have access to jobs that correlate with lower satisfaction, i.e. are of less quality.

\subsection{Employment conditions and opportunities}

To further examine why young highly educated men and women are not, on average, equally satisfied with all the aspects of their job, we will now examine the objectively 
defined employment conditions of these two sub samples. Table 2 shows the descriptive statistics for men and women separately. The last common reports the t-values of the differences between genders. This value indicates whether the differences between the two sub-samples are or are not statistically significant. ${ }^{10}$

\section{[Insert Table 2 here]}

If we take into account that this is a very specific sub sample of highly educated young individuals in the year 2000 in South Europe, the differences between the two genders are sticking. Table 2 shows that there are many statistically significant gender differences on employment conditions as well as on education choices and attainments. It is not our intention to claim that these differences are due to discrimination. This is just only one possible explanation. Other options are, for example, that women selfselect themselves into certain occupations (e.g. Macpherson and Hirsch, 1995) and women cannot negotiate their salary as well as men do (e.g., Solnick and Schweitzer, 1999).

Let's now turn to the job characteristics described in Table 2. Although this Table shows the sample means for all the variables used in the job satisfaction regression, we will here only focus on the relevant ones. The table shows that compared to men, women, on average, earn less, are less often self-employed, have a larger chance to have a fixed term contract (instead of a permanent one), work in smaller establishments, are

\footnotetext{
${ }^{10} \mathrm{~A}$ t-value higher than 1.96 indicates that the gender differences are statistically significant at $5 \%$.
} 
more often found in low-level qualified occupations ${ }^{11}$, and work more frequently in the 'medical care and social work' and 'teaching and training' sectors.

Men and women also differ regarding their education choices and achievements. On average, women have a lower degree of education (they are over represented among individuals with a 3-year degree -'diplomatura'-), and obtain less often the highest final grade (excellent). In the filed of study choice, there are also gender differences: women choose more often for humanities, social sciences, and medical sciences. Notice that medical sciences does not only include medicine but also a large set of other health studies, such as pharmacy, odontology, psychology, nursing, physiotherapy, and veterinary medicine.

After seeing the large differences existing on the objective situation of men and women, the logic next step is to examine whether women are still less satisfied than men once we control for the worse employment conditions and educational attainments and choices of women. For this we will need to econometrically analyze job satisfaction. This is the objective of next section.

\subsection{A complete model of Job Satisfaction}

Table 3 presents the Ordered Probit results for the five partial job satisfactions. The variable capturing personality has the expected sign and it is statistically significant for all partial job satisfaction. All the other variables included in the regression do not offer many surprises. The age of the respondent is included but its sign is often statistically

\footnotetext{
${ }^{11}$ This seems to indicate that, compared to men, women have more often a job for which they are over qualified. As argued by Hersch (1991) over education tends to correlate with a lower job satisfaction. It is pertinent to notice that, compared to most OECD countries, the problem of over education is particularly worrisome in Spain and Catalonia (Dolado et al., 2000).
} 
insignificant. Since the sample at hand has individuals only aged between 23 and 34, it is difficult to compare the age coefficient found here with the one in other studies.

Although for reasons of space we do not present the tables ${ }^{12}$, it is important to report that the results do not change when we do not include the variable capturing individual's personality. This means that the gender gap appearing in Table 3 is not due to systematic personality differences between men and women.

Looking at Table 3, one can conclude that while (present and past) employment conditions seem to be important determinants of job satisfaction, educational choices and achievements hardly play any role in job satisfaction. This seems to indicate that the effect (if any) of education on job satisfaction is captured by the job opportunities associated with educational attainments. Thus, the educational differences between men and women are only important to the extent that they translate into different job opportunities.

\section{[Insert Table 3 here]}

The results in Table 3 show that after controlling for a large set of job, individual and education characteristics as well as for individual personality traits, the gender gap only remains for satisfaction with promotion possibilities and appears for applicability of acquired knowledge. Thus, the gender gap disappears for satisfaction with earnings and job security. Sousa-Poza and Sousa-Poza (2000) find that the gender gap disappears in most countries once the researcher controls for job and other characteristics. In other

\footnotetext{
12 The results are available upon request.
} 
words, they find that the gender gap on job satisfaction is due to the worse employment conditions and perspectives that women have. In our case, this is only true for 2 out of 3 satisfaction in which we found a lower reported satisfaction for women. In addition, a gender gap appears in one other job satisfaction, namely satisfaction with applicability of acquired knowledge. For satisfaction with work content, we neither find a gender gap on the reported satisfaction nor in the regression analysis.

At this point, it is very important to notice that, even when controlling for individuals’ objective situation, we find a negative effect of being a women on two out of the five partial job satisfactions. In other words, the positive gender gap for women in job satisfaction (Clark, 2997; Kaiser, 2005) has disappeared and even inverted sign for highly educated young individuals. Young highly educated Catalan women seem to go to the job market with the same expectations as men do. When they get there, however, they are unable to reach the same employment conditions as their peer males. Therefore, they are less satisfied with their job.

Since the gender gap for satisfaction with earnings and job security disappears when controlling for job characteristics, we conclude that the reason why women report a lower satisfaction in these job domains is because of their employment conditions. Table 3 shows that, among others, wages and type of contract (fixed term, permanent or self-employed) are important determinants of satisfaction with earnings and with job security. Furthermore, in Section 3.2 we showed that women and men had statistically significant differences regarding these three variables. For satisfaction with earnings, the lower wages of women and the fact that they are less represented among selfemployed seem to be important contributors for the lower reported satisfaction. For 
satisfaction with job security, earnings and fixed term contracts appear to be the responsible.

The gender gap however does remain for satisfaction with promotion probabilities. In other words, including explanatory variables such as earnings, self-employment, and type of occupation, does not make the gender gap disappear. Since the gender gap remains after controlling for personality, the most obvious explanation for the negative coefficient for women is the exclusion of relevant variables. We argue that while it is easier to control for the objective situation related to satisfaction with earnings (wages) and satisfaction with job security (type of contract), it is much more difficult if not impossible to find objective measures capable to capture the true probability of promotion. This means that the gender gap found in satisfaction with promotion probabilities reflects the lower chance that women have to get promotion at their job. This is in accordance with other literature, which claim that in Spain there still exist a 'glass ceiling' for highly-educated women (De la Rica et al., 2006).

In satisfaction with applicability of acquired knowledge, a negative coefficient appears for women. This contrasts with the reported satisfaction, which does not show statistically significant differences between genders. Not surprising, this satisfaction is positively correlated with certain occupations, namely 'advising and consultancy', 'administration and accountancy', 'teaching and training', and 'R\&D'. All these occupations require very specific knowledge and therefore it is not common to find, e.g. a teacher who does not have a degree on teaching. The same holds for the consulting, accountancy and technical jobs. In comparison with the other job satisfaction dimensions, and together with satisfaction with work content, satisfaction with 
applicability of acquired knowledge is much related to the intrinsic aspects of job satisfaction. According to Kim (2005) women are more orientated towards the intrinsic aspects of their jobs, such as feelings of self-determination and personal development, rather than to the extrinsic job characteristics, such as financial rewards. Thus, the negative coefficient for gender after having controlled for job characteristics is in accordance with this literature.

\section{Conclusions}

In this paper we focus on explaining the gender gap on the labor market for recent higher education graduates in Catalonia (Spain). For this sample of young individuals, women report on average a lower job satisfaction than men on three out of the five job partial satisfactions. Although we should be careful in our conclusions, our empirical analysis suggests that the lower job satisfaction experienced or reported by young highly educated women can be largely attributed to the worse employment conditions they have. Educational achievements of women also differ from those of men. These differences could partly explain the worse employment conditions of women. In the regression analysis however educational achievements have hardly any effect on job satisfaction. This seems to indicate that the effect of education on job satisfaction goes mainly through working achievements. This is in accordance with the literature on job satisfaction, which usually does not find any statistical significant effect for education.

In 1997 Clark found that when controlling for job characteristics, women experienced a larger job satisfaction. He attributed that to the lower expectations women have when entering the labor market. More recent work (Kaiser, 2005; and Sousa-Poza and SousaPoza, 2003) indicated that women expectations were rising in the last decade. 
According to these authors, women exceptions have been increasing due to their better positioning in the labor market, i.e. women adapted to their improvements. This study indicates that young highly educated Catalan women have indeed adapted their expectations to the new times. Nevertheless, their real jobs achievements continue being of worse quality than those of their co-generational males. Therefore, these women experience and report a lower job satisfaction than men. This is true even when referring to highly educated individuals who were younger than 34 in the year 2000 in Catalonia, one of the most economically developed regions in Spain. This article cannot show whether the worse employment conditions and job satisfaction experienced by these women are due to discrimination in the labor market. Although this could be one explanation, an alternative one is that women select themselves into education tracks, sectors, and jobs were the labor conditions are worse. Irrespectively of the reason, policy oriented to promote women entrance to certain education paths and jobs would be welcome. This is desirable since present evidence indicates that higher job satisfaction of women in Europe would go hand by hand with increasing women participation in the labor market. 


\section{References}

Bono, Joyce E. and Timothy A. Judge, 2003. "Core self-evaluations: a review of the trait and its role in job satisfaction and job performance”. European Journal of Personality 17 (1): S5-S18.

Clark, Andrew E., 1997. "Job satisfaction and gender: why are women so happy at work?” Labour Economics 4(4): 341-372.

Clark, Andrew E., 1999. “Are wages habit-forming? Evidence from micro data”. Journal of Economic Behavior and Organization, 39(2): 179-200.

Clark, Andrew E., 2001. "What really matters in a job? Hedonic measurement using quit data”. Labour Economics 8(2): 223-242.

Clark, Andrew E. and Yannis Georgellis, 2004. "Kahneman meets the Quitters: PeakEnd Behaviour in the Labour Market”. Working Paper.

Clark, Andrew E. and Andrew J. Oswald, 1996. “Satisfaction and comparison income”. Journal of Public Economics 61(3) 359-381.

Clark, Andrew E., Andrew J. Oswald and Peter B. Warr, 1996. "Is job satisfaction Ushaped in age?” Journal of Occupational and Organizational Psychology, 69(1): 5781.

De la Rica, Sara, Juan J. Dolado and Vanesa Llorens, 2006. “Ceiling and floors: gender wage gaps by education in Spain”. Discussion Paper No. 1483.

Dolado, Juan J., Florentino Felgueroso and Juan Francisco Jimeno, 2000. "Youth labour markets in Spain: education, training and crowding out”. European Economic Review 44 (4-6), 943-956.

Drakopoulos, Stavros A. and Ioannis Theodossiou, 1997. "Job satisfaction and target earnings”. Journal of Economic Psychology, 18(6): 693-704.

European Commission, 2002. Employment in Europe 2002. http://ec.europa.eu/ employment_social/news/2002/sep/employment_in_europe2002.pdf

Ferrer-i-Carbonell, Ada and Paul Frijters, 2004. "How important is methodology for the estimates of the determinants of happiness?” The Economic Journal 114(497): 641659.

Freeman, Richard B., 1978. "Job satisfaction as an economic variable”. American Economic Review 68(2): 135-141.

Groot, Wim and Henriëtte Maassen van den Brink, 1999. “Job satisfaction and preference drift.” Economics Letters 63(3): 363-367. 
Hersch, Joni, 1991. "Education match and job match". Review of Economics and Statistics 73(1): 140-144.

Kaiser, Lutz C., 2005. “Gender job satisfaction differences across Europe: An indicator for labor market modernization”. DIW Working paper n. 537, Berlin, Germany.

Kim, Sangmook, 2005. “Gender differences in the job satisfaction of public employees: a study of Seoul metropolitan government, Korea”. Sex Roles 52 (9-10): 667-681.

Lykken, David and Auke Tellegen, 1996. “Happiness in a stochastic phenomenon”. Psychological Science 7 (3): 186-189.

Macpherson, David A. and Barry T. Hirsch, 1995. "Wages and Gender Composition: Why Do Women's Jobs Pay Less?” Journal of Labor Economics 13(3): 426-471.

Solnick, Sara J. and Maurice E. Schweitzer, 1999. "The Influence of Physical Attractiveness and Gender on Ultimatum Game Decisions”. Organizational Behavior and Human Decision Processes 79(3): 199-215.

Sousa-Poza, Alfonso and Andrés A. Sousa-Poza, 2000. “Taking another look at the gender/job paradox”. Kyklos 53(2): 135-152.

Sousa-Poza, Alfonso and Andrés A. Sousa-Poza, 2003. "Gender Differences in Job Satisfaction in Great Britain, 1991-2000: Permanent or Transitory?” Applied Economics Letters 10(11): 691-694.

Van Praag, Bernard M.S. and Ada Ferrer-i-Carbonell, 2004. Happiness Quantified: A Satisfaction Calculus Approach. Oxford: Oxford University Press.

Woittiez, Isolde and Jules Theeuwes, 1998. “Well-Being and Labor Market Status,” in: Stephen P. Jenkins, Arie Kapteyn and Bernard M.S. van Praag (eds.). The distribution of welfare and household production: International perspectives. pp. 211-230. Cambridge: Cambridge University Press. 
Table 1 Average satisfaction responses by dimension and gender

\begin{tabular}{lccccc}
\hline & Work content & Promotion & Earnings & $\begin{array}{c}\text { App. of acq. } \\
\text { knowledge }\end{array}$ & Job security \\
\hline Men & 5.2156 & 4.5649 & 4.0180 & 4.4710 & 4.9475 \\
Women & 5.2779 & 4.1999 & 3.8646 & 4.4666 & 4.7832 \\
All & 5.2534 & 4.3430 & 3.9249 & 4.4683 & 4.8475 \\
N responses & 4,391 & 4,385 & 4,378 & 4,390 & 4,381 \\
t-statistic difference & $(-1.3750)$ & $(6.2342)$ & $(2.8988)$ & $(0.0801)$ & $(2.8789)$ \\
\hline
\end{tabular}


Table 2 Job characteristics by gender

\begin{tabular}{|c|c|c|c|c|c|c|c|}
\hline & Men & Women & $\mathrm{t}$ - test & & Men & Women & t test \\
\hline Age & 27.17 & 26.25 & 15.34 & Low-level qualified occupations & 0.09 & 0.12 & -4.00 \\
\hline Personality traits & 0.44 & 0.47 & -5.66 & & & & \\
\hline \multirow[t]{2}{*}{ Doing further training } & 0.59 & 0.63 & -2.76 & Type of occupation & & & \\
\hline & & & & Corporate Management & 0.03 & 0.02 & 2.16 \\
\hline Wage (Euros/ year, gross) & & & & Advising and Consultancy & 0.11 & 0.09 & 2.30 \\
\hline less than 9000 Euros & 0.12 & 0.25 & -10.82 & Product Management & 0.05 & 0.02 & 6.70 \\
\hline [9000 - 12000) Euros & 0.11 & 0.19 & -7.64 & Technical support & 0.16 & 0.06 & 11.17 \\
\hline [12000 - 18000) Euros & 0.25 & 0.30 & -4.41 & Administ. \& Accountancy & 0.07 & 0.08 & -1.55 \\
\hline [18000 - 30000) Euros & 0.39 & 0.23 & 12.52 & Medical Care \& Social Work & 0.01 & 0.06 & -8.14 \\
\hline [30000 - 40000] Euros & 0.01 & 0.02 & 11.48 & Logistics, Distrib. \& Marketing & 0.03 & 0.02 & 1.64 \\
\hline \multirow[t]{2}{*}{ More than 40000 Euros } & 0.04 & 0.01 & 6.70 & Teaching and Training & 0.97 & 0.19 & -9.05 \\
\hline & & & & Design and Media & 0.02 & 0.02 & 0.87 \\
\hline Only one job experience & 0.34 & 0.33 & 0.19 & $\mathrm{R} \& \mathrm{D}$ & 0.11 & 0.41 & 9.18 \\
\hline Share of fixed contracts & 0.51 & 0.45 & 4.74 & Other qualified occupations & 0.23 & 0.27 & -3.43 \\
\hline How obtained their first job & & & & Working Region & & & \\
\hline by press appointments & 0.24 & 0.17 & 5.72 & Barcelona province & 0.71 & 0.69 & 1.68 \\
\hline by public competition & 0.07 & 0.10 & -2.80 & Tarragona province & 0.09 & 0.09 & -0.39 \\
\hline by agencies & 0.08 & 0.10 & -3.08 & Girona province & 0.08 & 0.01 & -2.72 \\
\hline by self-employed & 0.04 & 0.02 & 3.42 & Lleida province & 0.05 & 0.06 & -1.32 \\
\hline by job centre at university & 0.11 & 0.12 & -0.53 & Rest of Spain & 0.04 & 0.04 & 0.84 \\
\hline \multirow[t]{2}{*}{ by any other means } & 0.10 & 0.16 & -5.76 & In the EU & 0.02 & 0.02 & 1.08 \\
\hline & & & & Outside the EU & 0.01 & 0.01 & 1.31 \\
\hline \multicolumn{8}{|l|}{ Type of contract } \\
\hline Self-employed & 0.10 & 0.08 & 2.35 & Field of Study & & & \\
\hline Fixed term contract & 0.32 & 0.42 & -6.74 & Humanities & 0.10 & 0.15 & -5.01 \\
\hline Permanent contract & 0.56 & 0.47 & 5.68 & Social Sciences & 0.32 & 0.55 & -16.57 \\
\hline \multirow[t]{2}{*}{ No contract } & 0.02 & 0.03 & -1.48 & Experimental Sciences & 0.10 & 0.10 & 0.33 \\
\hline & & & & Medical Sciences & 0.03 & 0.10 & -8.81 \\
\hline University degree required & 0.20 & 0.18 & 1.92 & Science & 0.44 & 0.10 & 30.92 \\
\hline \multirow[t]{2}{*}{ No degree requirement } & 0.61 & 0.60 & 0.74 & & & & \\
\hline & & & & Degree obtained & & & \\
\hline Establishment size & & & & Architecture & 0.04 & 0.02 & 4.04 \\
\hline Less than $10=1$ & 0.16 & 0.22 & -4.68 & 'Diplomatura'(equiv. to B.A.) & 0.16 & 0.31 & -12.75 \\
\hline Between $[11,50]$ & 0.21 & 0.26 & -4.23 & Engineering & 0.39 & 0.08 & 30.16 \\
\hline Between $[51,100]$ & 0.11 & 0.12 & -0.53 & 'Llicenciatura'(equiv. to Master) & 0.41 & 0.59 & -12.83 \\
\hline Between $[101,250]$ & 0.12 & 0.08 & 4.24 & & & & \\
\hline \multirow[t]{2}{*}{ Between [251,500] } & 0.08 & 0.06 & 3.37 & Grade obtained & & & \\
\hline & & & & Pass ('aprovat') & 0.17 & 0.17 & -0.29 \\
\hline Previous job & & & & Pass- very good ('notable’) & 0.63 & 0.63 & -0.47 \\
\hline Student & 0.70 & 0.73 & -2.08 & Very good -Excellent & 0.18 & 0.18 & -0.01 \\
\hline Part-time related & 0.11 & 0.11 & 0.25 & Excellent & 0.02 & 0.14 & 2.55 \\
\hline Part-time non-related & 0.09 & 0.09 & -0.62 & & & & \\
\hline Full time related & 0.06 & 0.05 & 2.01 & & & & \\
\hline Full time non-related & 0.05 & 0.03 & 3.21 & & & & \\
\hline
\end{tabular}


Table 3 Job Satisfaction with 5 aspects, recent graduates, Ordered Probit

\begin{tabular}{lccccc}
\hline & Work content & $\begin{array}{c}\text { Promotion } \\
\text { Possibilities }\end{array}$ & Earnings & $\begin{array}{c}\text { App. of acquired } \\
\text { knowledge }\end{array}$ & Job security \\
\hline Gender & $-0.0014(-0.03)$ & $-0.1259(-3.17) \mathrm{a}$ & $0.0352(0.80)$ & $-0.0816(-1.81) \mathrm{c}$ & $0.0056(0.13)$ \\
Age & $-0.0161(-1.59)$ & $-0.0294(-2.97) \mathrm{a}$ & $-0.0367(-3.38) \mathrm{a}$ & $-0.0034(-0.34)$ & $-0.0139(-1.35)$ \\
Personality traits & $1.6593(14.00) \mathrm{a}$ & $1.6369(13.35) \mathrm{a}$ & $0.9612(7.96) \mathrm{a}$ & $1.7661(15.75) \mathrm{a}$ & $1.1811(9.67) \mathrm{a}$ \\
Doing further training & $-0.1008(-2.51) \mathrm{b}$ & $-0.0263(-0.68)$ & $-0.0187(-0.50)$ & $-0.0300(-0.72)$ & $-0.0366(-0.94)$
\end{tabular}

Wage (Euros/ year, gross) (ref. [18000 - 30000) Euros)

less than 9000 Euros

[9000 - 12000) Euros

$[12000-18000)$ Euros

$-0.3761(-5.23) \mathrm{a}$

$-0.3884(-5.27) a-1.3289(-15.61) a$
$-0.2928(-4.69) a-1.0281(-14.26) a$

$-0.0475(-0.64) \quad-0.5446(-7.31) \mathrm{a}$

$-0.2377(-4.67) \mathrm{a} \quad-0.1404(-2.83) \mathrm{a}-0.5677(-11.93) \mathrm{a}$

$-0.0184(-0.30) \quad-0.2440(-3.60) \mathrm{a}$

[30000 - 40000] Euros

$0.1045(1.30)$

$0.1508(2.01) \mathrm{b} \quad 0.6340(8.81) \mathrm{a}$

$-0.0130(-0.27) \quad-0.1231(-2.39) \mathrm{b}$

More than 40000 Euros

$0.3843(2.88) \mathrm{a}$

0.6046 (4.38)a $1.0049(7.45) \mathrm{a}$

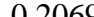

$-0.0514(-0.63)$

$\begin{array}{lllll}-0.0668(-1.45) & -0.1216(-2.76) \mathrm{a} & -0.0938(-2.30) \mathrm{b} & 0.0793(1.84) \mathrm{c} & 0.0032(0.08)\end{array}$

Only one job experience

$0.1834(2.80) \mathrm{a}$

$0.2283(3.65) \mathrm{a} \quad 0.1067(1.68) \mathrm{c}$

$0.1041(1.77) \mathrm{c}$

$0.1833(2.89)$

How obtained their first job (ref. by personal networks)

by press appointments

$-0.1086(-2.03) \mathrm{b}$

by public competition

$0.2255(2.79) \mathrm{a}$

$0.0391(0.75) \quad-0.0866(-1.74) \mathrm{C}$

$0.0409(0.77)$

$0.0361(0.69)$

$-0.2369(-3.36) \mathrm{a}$

$0.0809(1.02) \quad 0.0276(0.37)$

$0.2713(3.61) \mathrm{a}$

by agencies

$0.2399(1.43)$

$-0.0863(-1.20) \quad-0.0410(-0.56)$

$-0.0293(-0.40)$

$0.0517(0.32)$

by job centre at university

$0.0236(0.42)$

$\begin{array}{ll}.0624(3.68) \mathrm{a} & 0.0174(0.11)\end{array}$

$0.0517(0.32)$

$0.0178(0.29)$

$-0.0556(-0.71)$

by any other means

$-0.0131(-0.21) \quad-0.0372(-0.64)$

$0.1050(1.89) \mathrm{c}$

$0.1531(1.09)$

$-0.2086(-3.50) \mathrm{a}$

$-0.0360(-0.60)$

\section{Type of contract (ref. permanent)}

Type of contract: Self-employed

0.5133 (5.95)a

Type of contract: Fixed term contract

Type of contract: No contract

$0.1770(3.30) \mathrm{a}$

$0.3922(4.43) a \quad 0.4830(5.38) a$

$-0.0299(-0.57) \quad 0.2539(5.18) \mathrm{a}$

$0.6188(3.26) \mathrm{a}$

$0.3497(2.39) \mathrm{b} \quad 0.2669$ (1.77)c

$0.1895(2.31) \mathrm{b} \quad-0.3577(-4.33) \mathrm{a}$

$0.1441(2.79) \mathrm{a} \quad-0.8749(-16.19) \mathrm{a}$

$0.3347(1.90) \mathrm{c} \quad-0.6647(-3.93) \mathrm{a}$ 
University degree required

No degree requirement

Establishment size (ref. >500)

Less than $10=1$

Between [11,50]

Between [51,100]

Between [101,250]
Between [251,500]

$0.0834(1.33)$

0.2349 (4.25)a

$0.0659(1.02)$

$0.0024(0.04)$

$-0.1585(-2.84) \mathrm{a}$

$1311(2.08) \mathrm{b}$

0.4744 (8.50)a

$0.0672(-1.02)$

$-0.0408(-0.74)$

Type of occupation (ref. other qualified occupations)

Corporate Management

Advising and Consultancy

Product Management

Technical support

Administration and Accountancy

Medical Care and Social Work

Logistics, Distribution \& Mark.

Teaching and Training

Design and Media

R\&D

0.1982 (2.96)a

0.1939 (3.51)a

$0.0992(1.50)$

$-0.2277(-3.33) \mathrm{a} \quad-0.1445(-2.07) \mathrm{b}$

$-0.1403(-2.52) b \quad-0.0787(-1.53)$

$-0.0024(-0.04)$

$-0.1857(-2.87) \mathrm{a} \quad-0.0918(-1.43)$

$-0.1076(-1.63) \quad-0.0955(-1.51)$

$-0.0238(-0.33)$

$-0.1945(-2.90) \mathrm{a} \quad-0.1682(-2.52) \mathrm{b}$

0.2522 (3.86)a

0.1229 (2.38)b

$0.1551(2.28) \mathrm{b}$

0.1355 (2.06)b

$-0.1042(-1.49)$

$0.0547(0.82)$

$0.0585(1.06)$

$0.0169(0.27)$

$-0.0030(-0.05)$

$-0.0251(-0.36)$

occupations)

$0.0739(1.15)$

$0.1961(1.28) \quad 0.0751(0.46)$

$0.1216(1.83) \mathrm{c} \quad-0.0508(-0.79)$

$-0.0623(-0.60)$

$0.0491(0.48) \quad-0.1020(-1.04)$

$-0.1579(-2.30) \mathrm{b}$

$-0.0687(-1.04) \quad-0.1193(-1.75) \mathrm{C}$

$0.0863(1.06) \quad 0.0318(0.43)$

$-0.0141(-0.12) \quad-0.1603(-1.52) \quad 0.2667(2.23) \mathrm{b}$

$-0.1938(-1.66)$ c $\quad-0.0457(-0.41) \quad-0.1956(-1.91) \mathrm{c}$

$0.2790(3.96) \mathrm{a} \quad-0.3164(-4.35) \mathrm{a} \quad 0.2975(3.93) \mathrm{a}$

$0.0036(0.03) \quad-0.0855(-0.67) \quad-0.0877(-0.53)$

0.3976 (4.59)a

$-0.0316(-0.36)-0.1865(-2.26) \mathrm{b}$

$-0.8437(-10.94) a \quad-0.4762(-6.26) a-0.3562(-4.98) a$

Low-level qualified occupations

Working Region (ref. Barcelona region)

Tarragona province

Girona province

Lleida province

Rest of Spain

In the EU

Outside the EU
$0.0754(1.20)$

$0.2139(3.02)$

0.1709 (1.89)c

$0.1395(1.49)$

$0.1948(2.81) \mathrm{a}$

$0.2143(3.21) \mathrm{a}$

$0.2306(3.27) \mathrm{a}$

$0.0734(0.79) \quad 0.2003(2.15) \mathrm{b}$

$0.0962(1.03) \quad 0.3113(3.28)$

$-0.1434(-0.94) \quad-0.1417(-1.00) \quad 0.0960(0.73)$

$0.1869(0.81)$

$-0.0034(-0.01) \quad-0.0994(-0.46)$ $\begin{array}{cc}0.0225(0.15) & -0.1558(-1.19) \\ 0.1907(3.06) \mathrm{a} & 0.0559(0.84) \\ -0.0001(0.00) & 0.0371(0.35) \\ -0.0606(-0.92) & 0.0011(0.02) \\ 0.1918(2.58) \mathrm{b} & 0.0487(0.62) \\ 0.1972(1.66) \mathrm{c} & -0.1883(-1.47) \\ -0.1798(-1.59) & -0.0773(-0.72) \\ 0.3046(4.62) \mathrm{a} & -0.1742(-2.42) \mathrm{b} \\ 0.0894(0.75) & -0.1286(-0.83) \\ 0.4003(4.94) \mathrm{a} & -0.2195(-2.62) \mathrm{a}\end{array}$

$-0.5134(-6.67) \mathrm{a} \quad-0.0562(-0.75)$

$0.1015(1.55) \quad 0.0426(0.65)$

$0.0875(1.30) \quad 0.0810(1.16)$

$0.1532(1.73) \mathrm{c} \quad 0.1663(1.92) \mathrm{c}$

$0.2147(2.04) \mathrm{b} \quad 0.0537(0.53)$

$0.3746(2.59) \mathrm{b} \quad-0.1776(-1.30)$

$0.5423(2.37) b \quad-0.0917(-0.36)$ 
Previous job (ref. part time related)

Student

Part-time non-related

Full-time related

Full time non-related
$-0.0071(-0.12)$

$-0.0264(-0.32)$

0.1778 (1.85)c

$-0.1130(-1.09)$

Field of Study (ref. Social Sciences)

Humanities

Experimental Sciences

Medical Sciences

Science

$\begin{array}{ccccc}0.1189(1.51) & -0.0835(-1.17) & 0.0675(0.87) & -0.1550(-2.03) \mathrm{b} & -0.1075(-1.35) \\ -0.0377(-0.50) & -0.1749(-2.42) \mathrm{b} & -0.1323(-1.78) \mathrm{c} & -0.0218(-0.28) & -0.1269(-1.80) \mathrm{c} \\ 0.0522(0.55) & -0.2062(-2.43) \mathrm{b} & -0.1032(-1.11) & 0.4275(4.63) \mathrm{a} & -0.1604(-1.56) \\ -0.2319(-0.35) & -0.0863(-0.12) & -0.3095(-0.74) & 0.8917(2.24) \mathrm{b} & -0.2444(-0.52)\end{array}$

Degree obtained (ref. 'Llicenciatura'-equiv. to Master-)

Architecture

$-0.0476(-0.07)$

'Diplomatura'(equiv. to B.A.)

$0.0368(0.67)$

$0.0281(0.04)$

$-0.0307(-0.04) \quad 0.1048(0.25)$

$-0.0865(-1.67)$ с $\quad 0.0421(0.84)$

$-0.1355(-0.19) \quad 0.1111(0.27)$

$-0.8349(-2.03) b$

$-0.0673(-1.30)$

$-0.9009(-2.27) b$

$-0.1123(-0.24)$

$0.0716(1.35)$

$0.1092(0.23)$

Grade obtained (ref. Pass- very good ('notable'))

Pass ('aprovat')

Very good -Excellent

0.1618 (3.23)a

$0.0771(1.38)$

$-0.0278(-0.55) \quad 0.0347(0.67)$

$-0.0438(-0.81) \quad-0.0232(-0.46)$

$-0.0041(-0.08)$

$0.0404(0.78)$

$0.0020(0.04)$

0.1602 (1.18)
$0.1653(1.02)$

\title{
$\mathrm{N}$
} 3,441

\begin{abstract}
3,437
\end{abstract}
3,434

3,441

Wald c ${ }^{2}$ $870.32(0.00)$

0.0843

$808.44(0.00)$

0.0805

$993.12(0.00)$

Note: a, b, c denote significance at $1 \%, 5 \%$ and $10 \%$, respectively. 